\title{
Cultura Organizacional em Empresa Familiar: Uma Revisão Sistemática
}

\author{
Esraelyne Olimpio de Souza ${ }^{1}$; Thércia Lucena Grangeiro Maranhão ${ }^{2}$; \\ Nilda Maria de Clodoaldo Pinto Guerra Leone ${ }^{3}$; Gislene Farias de Oliveira ${ }^{4}$
}

\begin{abstract}
Resumo: O presente artigo tem como pergunta norteadora: Quais são os aspectos peculiares das empresas familiares? O objetivo principal da pesquisa é identificar na bibliografia eletrônica publicações entre o ano de 2010 a 2016 que apresentem as peculiaridades da cultura organizacional nas empresas familiares. A pesquisa foi realizada por meio de uma revisão sistemática e seus dados analisados segundo a metodologia da metassíntese. Foram selecionados artigos nas bases de dados acadêmicos SCIELO, BDTD E PEPSIC, utilizando-se os descritores: Empresa familiar e sucessão; valores organizacionais em empresas familiares; empresa familiar e cultura; empreendimentos familiares; empresa familiar. A escolha do tema ocorreu por notar que trabalhos nesta temática predominam nas produções científicas de administradores. Alguns pontos como lealdade, confiança entre as relações familiares, o baixo custo de transação, o respeito mútuo, o menor custo com recrutamento, a linguagem familiar, valores, hereditariedade, sucessão, gestão familiar, são características que segundo os autores podem se tornar vantagens competitivas quando potencializadas. Os aspectos peculiares identificados foram: influência da família na tomada de decisões; transmissão de valores pessoais do fundador; relações tradicionais; sucessão familiar; gestão familiar. A cultura organizacional esta relacionada com a tradição e a historia da organização.
\end{abstract}

Palavras chaves: Cultura Organizacional; Empresa Familiar; Sucessão.

\section{Organizational Culture in Family Business: A Systematic Review}

\begin{abstract}
This article has as guide answer: Which are the peculiar aspects of the family business? The principal objective of the research is to identify in the electronics bibliographic publications between the years 2010 and 2016 the publications that present the peculiarities of the organizations cultural in the families businesses. The research was performed by systematic reviewing and its data analysed by the methodology of the metasynthesis. Articles were selected in the academics data bases SCIELO, BDTD and PEPSIC, using the describers: family business and succession; organization values in family business; family business and culture; family enterprises; family business. The choice of the theme was to note that work on this theme prevalent in scientific administrators productions. Some points as loyalty, confidence between the family relations, the smaller cost of the transactions, the mutual respect, the smaller cost of the recruitment, the family language, values, heredity, succession, family management, according the authors are features that can turn up in competitive advantages when potentialized. The peculiar aspects identified were: family influence in the decisions; transmission of personal values of the founder; traditional relations; family succession; family management. The organizational culture is related with the tradition and the history of the organization.
\end{abstract}

Keywords: Organizational Culture; Family Business; Succession.

\footnotetext{
${ }^{1}$ Graduanda do curso de Psicologia pela UNILEÃO-Centro Universitário. E-mail: esraelyne@ gmail.com;

${ }^{2}$ Psicóloga , Graduada pela Faculdade de Ciências Humanas de Recife - ESUDA ,Especialista em Gestão do Trabalho e da Educação na Saúde pela Escola de Saúde Pública do Estado do Ceará .Pós- Graduanda da Faculdade de Medicina do ABC , do curso de Mestrado em Ciências da Saúde. Professora do Centro Universitário Dr. Leão Sampaio ;Membro do Comitê de Ética em Pesquisa da UNILEÃO. Coordenadora do Núcleo Cariri da ABRH-CE. E-mail: thercia@leaosampaio.edu.br

${ }^{3}$ Graduação em Administração de Empresas pela Escola Brasileira de Administração Pública. Mestrado em Administração pela Universidade Federal da Paraíba e Doutorado Em Ciências da Administração - Université de Grenoble II. Professora da Faculdade Leão Sampaio. Professora da Faculdade Vale do Salgado e Professora da Universidade Potiguar.

${ }^{4}$ Doutora em Psicologia Social pela Universidade Federal da Paraíba - UFPB; Pós doutorado em Ciências da saúde pela faculdade de Medicina do ABC, São Paulo. Docente na Faculdade de Medicina da Universidade Federal do cariri - UFCA. Contato: gislenefarias@gmail.com.
} 


\section{Introdução}

A cultura em geral aborda a acumulação das produções do homem em coletividade enquanto ser ativo no ambiente. Para compreender especificamente as produções culturais é necessário pesquisar a cultura em diferentes temáticas (MALANCHEN, 2013). A literatura da área de administração de empresas e psicologia organizacional aborda a cultura produzida dentro das organizações de trabalho, esta, ficou conhecida como cultura organizacional e passou a ser estudada em profundidade a partir dos anos 80 do século XX(ZANELLI, ANDRADE,BASTOS, 2004).

Ferreira (2013), informa que a cultura organizacional consiste no modo como a organização realiza suas atividades internas e externas e como os colaboradores se relacionam entre si, portanto, o modo de agir da organização é fruto da cultura organizacional, assim, a organização compartilha um sistema cultural próprio presente nas ideias, regras, hábitos, crenças, modos de tratar os clientes, fazer negócios e outros aspectos que a torna singular e distinta das demais presentes no mercado.

O sistema cultural é formado principalmente pela transmissão dos valores e crenças do fundador ao negócio, mas o compartilhamento deste sistema depende do grupo de colaboradores (SHEIN, 2009).

No Brasil encontra-se uma variedade de empreendimentos familiares, eles são pequenos ou grandes negócios iniciados e gerenciados por membros da mesma família. Estes empreendimentos possuem características próprias, sua marca e seus valores trazem como referências alguns aspectos que indiquem a qual família pertence, seja o nome do estabelecimento, a foto do fundador, os mitos e outros. A gestão da empresa familiar costuma está ocupada pelo fundador, em casos particulares, de morte ou aposentadoria a sucessão é passada para o filho primogênito e assim sucessivamente (CARNEIRO, 2008).

Compreendendo a importância do tema surge a grande pergunta: Quais são os aspectos peculiares das empresas familiares? Diante do exposto acima o objetivo principal do trabalho é identificar na bibliografia eletrônica publicações entre o ano de 2010 a 2016 que apresentem as peculiaridades da cultura organizacional nas empresas familiares, tendo como objetivos específicos, identificar os pressupostos da cultura organizacional em empresas familiares; 
descrever as atribuições do gestor enquanto mediador da cultura organizacional; identificar a contribuição da cultura organizacional na gestão de empresas familiares.

Durante os estudos da graduação, percebi que os psicólogos organizacionais produzem pesquisas em diversas temáticas, mas as pesquisas sobre cultura organizacional de empresas familiares predominam nas produções cientificas de administradores. Então, com o intuito de somar aos artigos produzidos e contribuir com pesquisas acadêmicas de estudantes e pesquisadores disponibilizando conteúdos que ajudam na escolha de temas futuro, propus este artigo. Optou-se pela revisão sistemática e metassíntese pela possibilidade de reunir e analisar os principais achados dos autores e revelar lacunas que devem ser investigadas cientificamente, bem como, propiciar uma síntese dos dados que podem resultar em um novo conhecimento. Deste modo, a revisão sistemática consiste em "uma revisão planejada para responder a uma pergunta específica e que utiliza métodos explícitos e sistemáticos para identificar, selecionar e avaliar criticamente os estudos e para coletar e analisar os dados destes estudos incluídos na revisão" (CASTRO, 2009, p. 01).

Com o intuito de explorar em detalhes os artigos e dissertações, utiliza-se da metassíntese, pois esta apresenta aplicabilidadepara analisar em detalhes resultados obtidos em abordagens qualitativas de pesquisas e conduzir a uma análise crítica dos dados (OLIVEIRA, et al., 2015).

Este trabalho analisa artigos e dissertações, selecionados através das seguintes bases de dados: SCIELO (Scientific Eletronic Library Online), BDTD (Biblioteca Digital Brasileiras de Teses e Dissertação) e PEPSIC (Períodos Eletrônicos em Psicologia), que foram escolhidas pela abrangência e consistência dos conteúdos científicos encontrados nestes sites. Após a seleção criteriosa que será apresentada no tópico da metodologia da pesquisa, o presente trabalho realiza a revisão sistemática e metassíntese de 16 trabalhos publicados a entre o ano de 2010 a 2016.

Este artigo segue a seguinte estrutura: apresenta no primeiro tópico uma revisão bibliográfica sobre a cultura organizacional e sobre empresa familiar, em seguida escreve a metodologia da pesquisa, expõe no terceiro tópico a análise e discursão dos dados que está dividido em quatro categorias: A primeira sobre empresa familiar, a segunda sobre gestão da empresa familiar, a terceira sobre empresa familiar e sucessão, a quarta sobre cultura organizacional em empresa familiar, finalizando com as considerações finais. 


\section{Metodologia}

O presente trabalho propõe uma revisão sistemática e metassíntese de artigos e dissertações de mestrado. As definições elaboradas tem a finalidade de identificar possíveis relações entre variáveis e conduzir a uma análise crítica da produção científica (GIL, 2010).

Para um estudo ser considerado uma revisão sistemática precisa mostrar claramente comofoi construído, pois a característica peculiar deste método é apresentar possibilidade de ser repetido e reproduzido (GOMES e CAMINHA, 2014).

Medina e Pailaquilém (2010), identificam que a revisão sistemática é um método útil e aplicável em diversas áreas de conhecimento, mas ainda pouco explorada, consiste em uma prática eficiente para coletar dados existentes e ajudar a definir agendas e temáticas de trabalhos futuros, assim, o presente trabalho utiliza deste método para reunir os principais achados de autores acerca da cultura organizacional e empesa familiar, publicados desde o ano de 2010 até março de 2016.

A interpretação dos resultados segue a metodologia da metassíntese que proporciona uma análise crítica das publicações e uma articulação dos resultados encontrados, disponibilizando novos conhecimentos (OLIVEIRA, et al., 2015).

Segue logo abaixo os passos para construção deste artigo de revisão sistemática e os critérios de inclusão e exclusão empregados.

Para a seleção das bases de dados eletrônicos realizou-se uma pesquisa na internet com a finalidade de encontrar bases de dados digitais que oferecem publicações abrangentes e fontes consistentes de pesquisa na área de psicologia, administração, economia, ou áreas afins. Optou pelas bases de dados que apresentam publicações brasileiras: SCIELO ( Scientific Eletronic Library Online), BDTD (Biblioteca Digital Brasileiras de Teses e Dissertação) e PEPSIC (Períodos Eletrônicos em Psicologia). A escolha ocorreu por encontrar através destes sites uma variedade de conteúdos consistentes e de interesse desta revisão. Foram visitadas também as bases de dados PSICODOC, PSICOINFO, EMBASE, MEDILINE, mas nelas não continham as publicações desejadas.

Os critérios empregados para a seleção e filtro dos artigos e dissertações foram os seguintes: publicações eletrônicas; nacionais; idioma português; publicados em sites ou revistas; produzidos e publicados a partir do ano de 2010 a 2016; apresentar conteúdo claro e 
sucinto; indicar no título ou no resumo o objeto estudado; o objeto de estudo fazer relação com a cultura organizacional ou empresa familiar e esta relação esta sinalizado no título ou resumo; pesquisas qualitativa.

Os descritores utilizados nas buscas foram: Empresa familiar e sucessão; valores organizacionais em empresas familiares; empresa familiar e cultura; empreendimentos familiares; empresa familiar.

As consultas aos bancos de dados ocorreram nos dias 30 e 31 de março de 2016. Inicialmente buscou as dissertações de mestrado no site da BDTD. Ao colocar no campo de pesquisa do site o primeiro descritor (empresa familiar e sucessão) sem definir os filtro, visualiza-se uma grande quantidade de dissertações, então optou-se por usar os filtros em todos os descritores, para fins de refinamento. Logo, preencheu no menu de refinamento as opções de ano de publicação, nacionalidade e idioma, marcando a opção por publicações a partir do ano de 2010 até o ano de 2016, de nacionalidade brasileira e, em língua portuguesa. Os mesmos passos foram utilizados nas bases de dados PEPSIC e SCIELO, sendo que, nestas pretendeu-se selecionar artigos.

Diante dos achados realizou-se uma leitura dos títulos e em seguida dos resumos, em casos de dúvidas quanto a inclusão dos trabalhos, efetuou-se uma leitura flutuante do texto que consiste em uma leitura parcial ou total com o intuito de se aprofundar no conhecimento do objeto de estudo (OLIVEIRA, et al., 2015).

Alguns trabalhos foram desabilitados por: não apresentarem texto completo; pelo servidor não abrir; por não possuir relação com o assunto pesquisado; estarem repetidos; apresentar-se em linguagem estrangeira; publicações antes do ano de 2010; pesquisar instituições públicas; apresentar predominância de dados quantitativos; apresentarem pouca correlação do objeto de estudo com a cultura organizacional ou empresa familiar. A desobediência aos critérios de inclusão torna as publicações desabilitadas para este artigo.

Ao final das buscas foram identificados no total 66 trabalhos, sendo que 41, foram desabilitados por não apresentarem conteúdos condizentes com os objetivos proposto e nãoobedecerem aos critérios de inclusão; 25 passaram por uma leitura flutuante para identificar consonâncias com os critérios de inclusão. Destes, foram rejeitados 09 por apresentarem pouca correlação do objeto de estudo com a cultura organizacional. Logo foram 
Id on Line Revista Multidisciplinar e de Psicoloqia

Id on Line Multidisciplinary and Psycology Journal

habilitados 16 trabalhos, sendo 10 artigos e 06 dissertações de mestrado, os quais nortearão esta produção científica.

\section{Fluxograma do Estudo:}

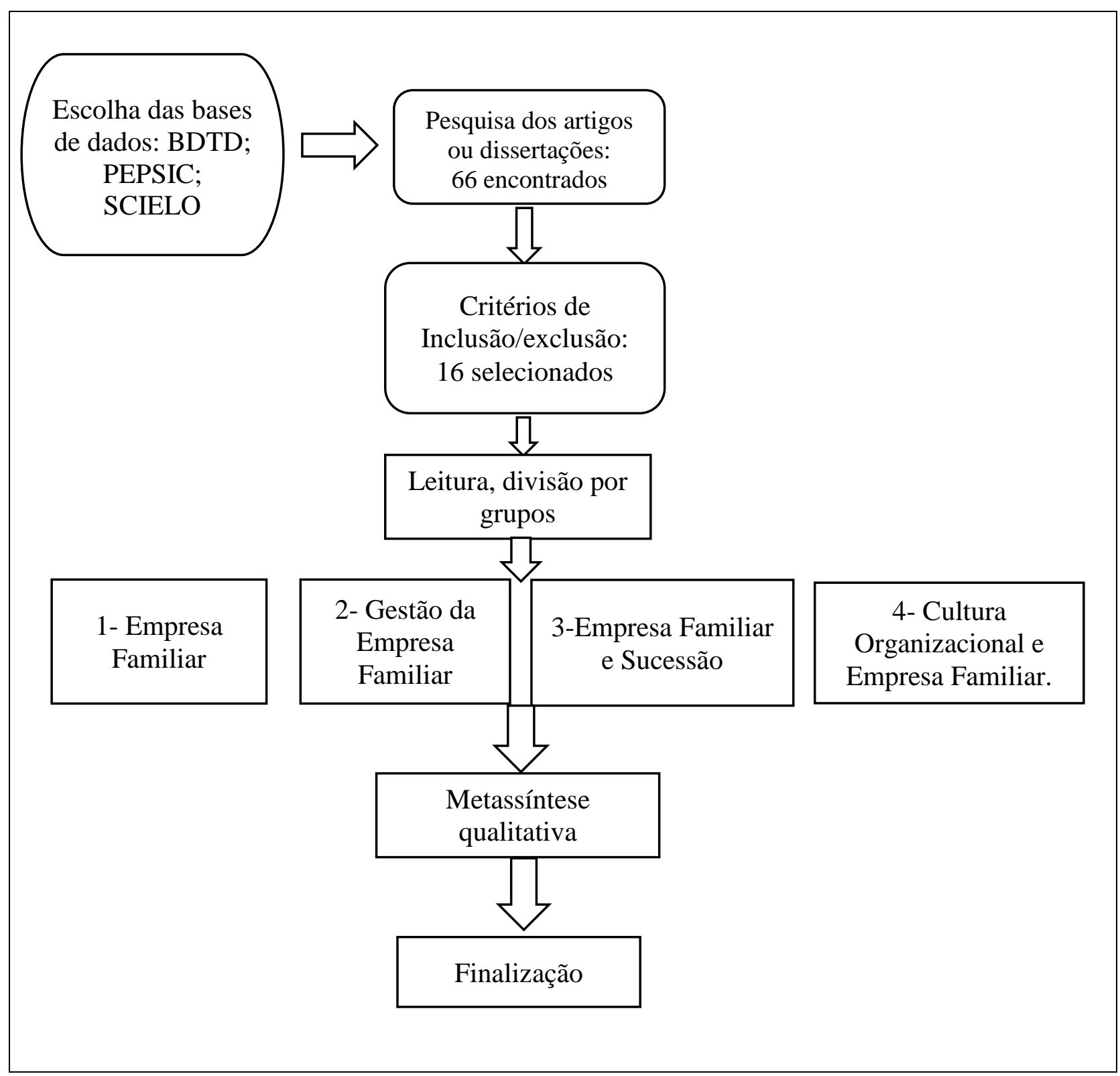

FONTE: Souza (2016) 


\title{
Cultura Organizacional
}

Cultura organizacional consiste em aspectos que a organização construiu e reforçou ao longo do tempo por seus processos e relações. A percepção que os funcionários ou clientes têm de uma empresa não vem de pensamentos inatos, constitui-se a partir do que a empresa mostra ser e do contexto social onde está inserida. O sistema cultural torna-se o principal aliado no processo de institucionalização, pois as simbologias, as histórias e as justificativas das ações, são compartilhadas pelos grupos e internalizadas de modo a afetar o agir, o pensar, e sentir dos colaboradores (FERREIRA, 2013).

Uma organização contém princípios e valores e estes, direcionam o comportamento e oferecem fundamentos para escolha do deve ou não ser feito, o autor Schein considerado um dos grandes pesquisadores da cultura organizacional fala que:

\begin{abstract}
A cultura organizacional é um padrão de pressupostos básicos compartilhados que um grupo aprendeu ao resolver seus problemas de adaptação externa e integração interna e que funcionou bem o suficiente para ser considerado válido e ensinado a novos membros como a forma correta de perceber, pensar e sentir com relação a esses problemas (SCHEIN 2009, p. 16).
\end{abstract}

Portanto, os comportamentos que os colaboradores exercem em ambiente de trabalho tem relação com o seu aprendizado e a interação com as pessoas que transmitem a cultura da organização. Por consequente, problemas constantes de rotatividade, desempenho e insatisfação, podem ter relação com a cultura empregada.

Corroborando com a ideia do autor citado acima Dias(2013) compreende a cultura organizacional, como uma das capacidades da empresa, que resulta de um processo longo e constante com o intuito de tornar comum a todos os membros um conjunto de normas e valores que identificam a empresa. A cultura organizacional de uma empresa é específica, difícil de ser imitada, pois abrange aspectos objetivos e subjetivos desenvolvidos pelos fundadores e por todos os que a integram, por isso mesmo pode se converter em importante fonte de vantagem competitiva As empresas utilizam recursos técnicos e administrativos para se manterem ativas e competitivas, deste modo a singularidade delas está na maneira de operar, as técnicas empregadas são consideradas apenas facilitadores neste processo (FERREIRA, 2013). Os mesmos instrumentos de gestão podem ser usados por diferentes 
empresas do mesmo ramo de atividade, mas a efetividade de implantações destes instrumentos depende de como o colaborador investe em sua realidade institucional. Russo (2010), descreve a cultura organizacional como um sistema capaz de ajudar a antever comportamentos, dessa forma, conhecer a cultura da organização permite desenvolver estratégias eficazes de intervenção.

Se a empresa oferecer suporte para o compartilhamento dos aprendizados organizacionais, a eficiência e eficácia almejada, são mais prováveis de serem alcançadas, pois os colaboradores estarão alinhados (ROTHMANN E COOPER, 2009). Zanelli, Andrade, Bastos (2004), ressalta que estudar a cultura é procurar entender questões simbólicas próprias da dinâmica organizacional.

Para Russo (2010), os valores ocupam posições centrais na cultura e são internalizados, vivencias frequentescom eles torna-o imperceptívelpois passam a ser naturalizados por quem compartilha dos mesmos valores. Portanto, para compreender a cultura organizacional é preciso saber que ela se mantém em coletividade e necessita ter um consentimento grupal e um ambiente propício para o compartilhamento de suas ideias principais.

São três os componentes que constituem os níveis da cultura organizacional: artefatos, valores compartilhados e pressuposições básicas. Em primeira instância estão os artefatos, compostos por eventos, coisas visuais ou auditivas que sinalizam como é a cultura da empresa. Já os valores compartilhados compõem o lugar central da cultura e sofrem fortes influências dos valores do fundador, sendo responsáveis por atribuir sentido ao trabalho e guiar o comportamento. O terceiro componente as pressuposições básicas constituem o nível mais profundo da cultura organizacional, “[...] são as crenças inconscientes, percepções, sentimentos e pressuposições dominantes e nos quais as pessoas acreditam". Percebe-se que a identificação da cultura organizacional não é uma tarefa simples, por se apresentar em diferentes níveis necessita de instrumentos eficazes para ser diagnosticada (CHIAVENATO, 2008, p. 175).

Como foi mencionada a cultura organizacional promove sentido aos afazeres e constitui-se não apenas de aspectos visíveis, mas também de formas cognitivas de organizar a realidade, como a expressão dos valores, crenças, costumes, hábitos, ideias e padrões de comportamento. 
Ao iniciar um empreendimento os precursores transmitem sua própria maneira de operar, seus valores pessoais e familiares aos poucos se tornam valores organizacionais, e as práticas decorrentes trazem aprendizado que são absorvidos sucessivamente promovendo um referencial de atuação que obteve êxito. Um ambiente econômico de trocas produtivas permite o surgimento de mitos e crenças e nas empesas familiares também propicia ao fundador uma valorização do seu legado e deste jeito, ele exerce forte influência no desenvolvimento da cultura organizacional (ROTHMANN E COOPER, 2009).

Seguindo os conhecimentos do mesmo autor, as empresas adotam medidas que valorizam e mantém os principais aspectos que acreditam e promovem a linearidade dos colaboradores. O Setor de RH é importante para este objetivo, pois os valores pessoais e características comportamentais dos novos recrutados devem ser criteriosamente analisados, para identificar se ele é capaz de absorver a cultura da organização e adaptar-se a ela.

\section{Empresa Familiar}

$\mathrm{Na}$ história econômica do Brasil as empresas familiares fizeram-se presentes, contribuíram e ainda contribuem na economia nacional. No país encontramos a Itaú, Votorantim, pão de açúcar, Gerdau, que se mantém no mercado durante muitos anos. As empresas familiares sejam grandes ou pequenas, juntas somam parte do PIB nacional e geram emprego e renda para milhares de pessoas. Existem de 6 a 8 milhões de empresas no país, sendo que $90 \%$ são familiares (SEBRAE, 2005).

Uma empresa de qualquer ramo de atividade pode ser iniciada por um membro de uma família que realiza seu sonho ou necessidade de empreender, esta inicialmente pode se caracterizar como um negócio particular, mas conforme a permanência no mercado e as características que adquire ao longo do tempo podem passar a ser considerada uma empresa familiar (CARNEIRO, 2008).

Diante a importância e representatividade do tema vários estudos etentam clarificar este segmento dentre estudiosos que adotaram tipologias que retratam do ciclo de vida das 
organizações estudando as tipologias de Adizes (1990), de Mendhan (1989) e de Leone (1994), (LEONE, 2006) ,contudo elegemos para o artigo a tipologia de Leone.

Iniciamos o processo a partir do pressuposto que identifica o ciclo de vida da empresa, adotamos a tipologia apresentada por Leone (1994), que reconhece as etapas ou estágios desde a criação até a morte da organização. Podemos definir os estágios como: primeiro estágio: existência/criação da empresa; segundo estágio: manutenção; terceiro estágio: êxito/expansão; e quarto estágio: desenvolvimento; quinto estágio: utilização máxima dos recursos; o 6o e último: esclerose (LEONE , 2006).

A sucessão é uma ocorrência ambicionada por boa parte das empresas familiares, uma vez que, ela assegura a permanência destas empresas no mercado. Geralmente o sucessor é o filho primogênito, pois a regra de sucessão consiste no contrato informal da hereditariedade. Quando o desejo de trabalhar na propriedade da família não é o sonho do filho sucessor, surgem as dificuldades e conflitos, já que a responsabilidade em guiar o negócio da família pode não satisfazer expectativa profissional do filho (DRUCKER, 2014).

Nishitsuji (2009, p.8), relata que "uma empresa familiar é aquela em que a sucessão da diretoria está ligada ao fator hereditário e onde os valores institucionais da mesma, identificam-se com um sobrenome da família ou com a figura do fundador". As características da empresa familiar também estão ligadas ao tempo de permanência no mercado, para deixar de ser um empreendimento particular necessita ter planos de sucessão ou está na segunda geração.

Morais (2006, p.45), afirma que "Na estruturação organizacional, a empresa de origem familiar pouco difere das não familiares. $\mathrm{O}$ fator que as diferencia encontra-se no ambiente interno da organização a influência da família-proprietária, mais especificamente a do fundador". Assim sendo, os princípios familiares, valores presentes na família, e as relações de afetivas são um grande empasse na constituição da empresa.

A confiança é uma característica valorizada na empresa familiar, por isso, cargos de gerência é dado para amigos, familiares, ou funcionários com muito tempo de serviço. É importante que a família reconheça qual o seu papel e saiba separar os objetivos da empresa dos seus próprios objetivos familiares (CARNEIRO, 2008).

O sistema tradicional em referência a família difere em grande parte das características familiares contemporânea. A modernidade permitiu modificações no núcleo familiar e 
também nas relações econômicas, hoje o pai pode não ser mais o único provedor da casa, mas nas empresas familiares o poder de decisão ainda é atribuído ao patriarca (BOTTOLI, 2012).

Atualmente vivemos em um mundo tecnológico de mudanças constantes que exige a capacitação intelectual para acompanhar a atualização de conhecimentos, o alto nível de competitividade exige das organizações a produção da inovação (BOTTOLI, 2012). Nos dados obtidos pelo SEBRAE na pesquisa feita no ano de 2005, alerta para a necessidade das empresas familiares trabalharem com a profissionalização e o planejamento de sucessão, por causa do baixo índice de sobrevivência destas organizações. A sobrevivência na terceira geração é apenas de 5\% de um total de 100 empresas familiares.

Podemos notar que as empresa familiares desempenham uma papel significativo no desenvolvimento econômico do país e preservam características próprias que mantém sua singularidade. Hoje os valores são sua maior vantagens competitivas, no entanto, nem sempre estes valores são considerados importantes, mais facilitam o alcance dos objetivos (NISHITSUJI, 2009).

Silva (2006, p. 42), fala que "montar um negócio em família e montar sua gestão ligada aos laços de parentesco sempre foi em toda a trajetória do sistema capitalista, uma forte tendência”. A cultura organizacional ajuda a organização a se estabelecer e se desenvolver, mas, para isto é necessário que sejam respeitados os sistemas particulares de gestão e ser considerada a participação da família.

Ao enfrentarem problemas organizacionais ou de mercado as empresa podem recorrer à cultura organizacional para entender como são estabelecidos esses problemas. Os funcionários exercem um papel importante por serem responsáveis em fazer o negócio funcionar (SILVA, 2006).

\section{Análise e Discussão}

Um total de 16 trabalhos foram selecionados, estes possuem data de publicação variada, quatro são do ano de 2010, dois do ano de 2012, sete do ano de 2013 e três do ano de 2014. Podemos perceber que o número de estudos publicados passa por constantes variações, 
tendo um aumento no número de pesquisas no ano de 2013, mas voltando a decrescer em 2014. Percebe-se uma lacuna de publicações nos anos de 2011, 2015 e 2016.

As áreas acadêmicas que os autores destinaram as pesquisas foram, administração, psicologia, direito e gestão do conhecimento, constatou maior predominância de estudos na área de administração chegando a 13 publicações, as demais com apenas 1 estudo em cada área. Isso mostra que a psicologia organizacionais é pouco utilizada para pesquisas nesta temática, necessitando de desenvolvimento de estudos que viabilize a utilização das ciência psicológicas, pois esta pode ser útil para a compreensão da relação entre família e propriedade e para o entendimento das influências psicológicas da cultura organizacional.

As cidades de origem de realizações dos trabalhos foram em Rio de Janeiro, Salvador, Fortaleza, São Paulo, Curitiba, Minas Gerais e Porto Alegre, as predominâncias de pesquisas foram no Rio de Janeiro chegando a 05 publicações, e São Paulo com 04 publicações, as demais cidades com apenas 01 publicação. Justifica a predominância de estudos realizados nestas cidades, pois possuem uma concentração maior de organizações que operam nestes dois territórios.

Witter (2006) citado por Oliveira. et al., (2015), propõe explorar os artigos colhendo informações de interesse para serem analisadas, na revisão é importante considerar o autor, método, tipo de estudos, instrumentos utilizados na coleta de dados, dentre outras de interesse do pesquisador.

Oliveira, et al. (2015, p 128) aponta que "conforme recomenda a literatura inicialmente foi feira uma leitura flutuante para, posteriormente, fazer-se uma leitura mais minuciosa, a qual permitisse uma melhor compreensão das informações. Posteriormente pretendeu-se a separação dos textos em categorias". Utilizando desta estratégia os artigos selecionados passaram por uma leitura fragmentada, primeira foi lido o referencial teórico com o intuito de buscar informações que abordasse a cultura organizacional e/ou empresa familiar, em seguida foram lidos parcialmente os resultados e, logo após, as considerações finais. Os trabalhos selecionados foram agrupados em categorias e o descritor encontrado no título ou no resumo classifica em qual categoria estará o trabalho, sendo essas categorias: 1Empresa Familiar, 2- Gestão da Empresa Familiar, 3-Empresa Familiar e Sucessão, 4- Cultura Organizacional e Empresa Familiar. 
Categoria 1 - Empresa Familiar

Nesta categoria foram agrupados os trabalhos que abordam conteúdos relativo a empresa familiar. Por empresa familiar, neste trabalho, consideram-se organizações particulares, que mantém em cargos de alta gestão o próprio fundador ou sucessor, e possui uma ou mais famílias influenciando as decisões do negócio (FREIRE, et al., 2010).

O quadro 01, apresenta os artigos selecionados que compõe a categoria 1 e os principais achados de cada autor.

Quadro 01. Empresa Familiar

\begin{tabular}{|c|c|c|c|c|}
\hline Titulo & Autor/ano & $\begin{array}{l}\text { Tipo de } \\
\text { Estudo }\end{array}$ & Amostra & Resultados \\
\hline $\begin{array}{l}\text { Estudo dos fatores que } \\
\text { determinam } r \text { a } \\
\text { formação do capital } \\
\text { social familiar em } \\
\text { empresas familiares na } \\
\text { região sul de Minas } \\
\text { Gerais }\end{array}$ & $\begin{array}{l}\text { ANDRADE, } \\
\text { Daniela } \\
\text { Meirelles. et } \\
\text { al. } \\
2013\end{array}$ & $\begin{array}{l}\text { Exploratória, } \\
\text { do tipo } \\
\text { survey }\end{array}$ & $\begin{array}{l}120 \\
\text { Empreendiment } \\
\text { os familiares }\end{array}$ & $\begin{array}{lrr}\text { As normas } & \text { éticas } \\
\text { sedimentadas e enraizadas } \\
\text { na cultura do } \\
\text { empreendimento familiar } \\
\text { se difundem por meio do } \\
\text { dialogo colaborativo. }\end{array}$ \\
\hline $\begin{array}{l}\text { Um estudo sobre o uso } \\
\text { da intuição como } \\
\text { facilitadora rá no } \\
\text { processo decisório em } \\
\text { empresas familiares }\end{array}$ & $\begin{array}{l}\text { SÁ, José } \\
\text { Antonio } \\
\text { Mograbi de. } \\
2013\end{array}$ & $\begin{array}{l}\text { Exploratório, } \\
\text { combinado, } \\
\text { de caráter } \\
\text { quanti- } \\
\text { qualitativo, }\end{array}$ & $\begin{array}{lr}\text { Ouvindo } & \text { a } \\
\text { opinião de } & 20 \\
\text { gestores } & \text { de } \\
\text { empresas } & \\
\text { familiares } & \text { de } \\
\text { médio e grande } \\
\text { porte }\end{array}$ & $\begin{array}{l}\text { Os } r \text { resultados } \\
\text { demonstraram haver maior } \\
\text { tendência ao uso de } \\
\text { procedimentos eminente- } \\
\text { mentes racionais entre } \\
\text { gerentes, enquanto os } \\
\text { presidentes se mostraram } \\
\text { mais abertos ao uso da } \\
\text { intuição, como diferencial } \\
\text { de gestores competentes. }\end{array}$ \\
\hline $\begin{array}{l}\text { Estruturação da } \\
\text { Estrutura } \\
\text { Organizacional: O } \\
\text { Caso de uma Empresa } \\
\text { Familiar }\end{array}$ & $\begin{array}{l}\text { SILVA, } \\
\text { Clóvis L. } \\
\text { Machado da; } \\
\text { FONSECA, } \\
\text { Valéria Silva } \\
\text { da. } \\
2010\end{array}$ & $\begin{array}{l}\text { Estudo } \\
\text { caso }\end{array}$ & $\begin{array}{l}\text { Uma } \\
\text { organização } \\
\text { familiar, } \\
\text { localizada no sul } \\
\text { do país }\end{array}$ & $\begin{array}{l}\text { Considera-se que os } \\
\text { padrões institucionais e as } \\
\text { circunstâncias situacionais } \\
\text { atuaram como propulsores } \\
\text { da dinâmica de funcio- } \\
\text { namento da organização } \\
\text { focalizada, cujo entendi- } \\
\text { mento, efetuado de acordo } \\
\text { com os valores predomi- } \\
\text { nantes em seu universo } \\
\text { simbólico, ocasionou a } \\
\text { estruturação da estrutura } \\
\text { organizacional. }\end{array}$ \\
\hline $\begin{array}{l}\text { Relações entre poder e } \\
\text { subjetividade em uma } \\
\text { organização familiar }\end{array}$ & $\begin{array}{l}\text { LOPES, } \\
\text { Fernanda } \\
\text { Tarabal; } \\
\text { CARRIERI, }\end{array}$ & $\begin{array}{l}\text { Pesquisa } \\
\text { qualitativa }\end{array}$ & $\begin{array}{l}\text { Histórias } \\
\text { de vida dos três } \\
\text { filhos do } \\
\text { fundador de uma }\end{array}$ & $\begin{array}{l}\text { As empresas familiares não } \\
\text { deixam de ser empreendi- } \\
\text { mentos econômicos mesmo } \\
\text { sendo intensas em afe- } \\
\text { tividade, sendo os filhos }\end{array}$ \\
\hline
\end{tabular}




\begin{tabular}{|l|l|l|l|l|}
\hline & Alexandre; & & empresa familiar & $\begin{array}{l}\text { vítimas dos mesmos estra- } \\
\text { tagemas que diversos auto- } \\
\text { SARAIVA, } \\
\text { Luiz Alex denunciam em } \\
\text { empresas capitalistas por } \\
\text { Silva. }\end{array}$ \\
2013 & & & $\begin{array}{l}\text { aderirem a um sonho que } \\
\text { não lhes pertence, mas que } \\
\text { lhes cabe manter vivo. }\end{array}$ \\
\hline
\end{tabular}

São referenciados os seguintes autores: Andrade et al.(2013),Sá (2013), Silva e Fonseca (2010), Lopes, Carrieri e Saraiva (2013). Os 04 trabalhos apresentam metodologia de pesquisas diferenciadas, com isso permite entender a temática por diferentes vertentes. Em relação à amostra total, o número de artigos é representativo e permite inferir que é um tema relativamente bem abordado na literatura.

Identificou-se que diferentes definições foram empregadas para fazer referência às empresas familiares, os autores selecionaram na bibliografia uma definição conveniente e utilizaram na pesquisa segundo suas próprias concepções de inclusão. Andrade et al. (2013), afirma claramente que "Um aspecto central relativo aos estudos sobre organizações familiares diz respeito à ausência de um corpo teórico convergente, unificado e maduro". Nos estudos de caso os autores alertam o cuidado para não generalizar os dados, pois cada organização é singular.

Sá (2013), adota o conceito de empresa familiar como a organização que se mantém ativa no mercado a pelo menos duas gerações, e possuem ligações familiares. Silva e Fonseca (2010), destacam a organização como parte elementar de um sistema de relações que são afetadas, não apenas por aspectos financeiros e técnicas, mas também, por fatores relativos de legitimidade. Lopes, Carrieri e Saraiva (2013) acrescenta que a vivência parental perpassa por relações de poder e controle da subjetividade.

O diálogo é apresentado como um instrumento que minimiza problemas relacionados à mudança e promove a tomada de decisão mais segura. Andrade. et al., (2013), o dialogo é visto por este autor como instrumento colaborativo que difunde as normas éticas presentes na cultura da organização. Esta questão expressa sobre o diálogo colaborativo mostra a primordial importância do entendimento deste, já que funciona como instrumento na transferência da cultura organizacional.

Apesar de tratarem as empresas familiares como ricas em afetividade, aborda ser pouco considerada a intuição dos gestores e colaboradores, prevalecendo as evidências 
numéricas. $\mathrm{O}$ fundador mostra interesse por esse comportamento intuitivo, mas não estimula a utilização, ficando privada para uso da alta gestão (ANDRADE. et al., 2013)

Alguns pontos como lealdade, confiança entre as relações familiares, o baixo custo de transação, o respeito mútuo, o menor custo com recrutamento, a linguagem familiar, valores, hereditariedade, sucessão, gestão familiar, são, características que segundo os autores podem se tornar vantagens competitivas quando potencializadas. Potencializar o que a diferencia no mercado é um vantagemà continuidade do negócio (ANDRADE. et al., 2013;SÁ, 2013).

A profissionalização da empresa familiar apresenta-se como uma mudança necessária para cessar os problemas organizacionais e de gestão, mas pouco abordam sobre a influência da família na tomada de decisões.

\section{Categoria 2- Gestão da Empresa Familiar}

Nesta categoria foram agrupados os trabalhos que abordam conteúdos relativos à gestão da empresa familiar. No quadro 02 visualizamos algumas informações destes trabalhos incrementados na categoria 2.

Quadro 02. Gestão da Empresa Familiar

\begin{tabular}{|c|c|c|c|c|}
\hline Titulo & Autor/ano & $\begin{array}{l}\text { Tipo de } \\
\text { Estudo }\end{array}$ & $\begin{array}{c}\text { Amostra } \\
\text { Ano }\end{array}$ & Resultados \\
\hline $\begin{array}{l}\text { A gestão ordinária dos } \\
\text { pequenos negócios: outro } \\
\text { olhar sobre a gestão em } \\
\text { estudos organizacionais }\end{array}$ & $\begin{array}{l}\text { CARRIER, } \\
\text { Alexandre } \\
\text { de Pádua. } \\
\text { PERDIGÃ } \\
\text { O, Denis } \\
\text { Alves. } \\
\text { AGUIAR, } \\
\text { Ana Rosa } \\
\text { Camillo. } \\
2014\end{array}$ & $\begin{array}{l}\text { Revisão } \\
\text { de } \\
\text { literatura }\end{array}$ & $\begin{array}{l}\text { Literatura } \\
\text { especializada }\end{array}$ & $\begin{array}{l}\text { Algumas pessoas exercem a } \\
\text { gestão de seus negócios pautada } \\
\text { na preservação de práticas } \\
\text { aprendidas em sua socialização } \\
\text { primária e secundária, no } \\
\text { cotidiano de seus negócios, } \\
\text { como que mantendo uma } \\
\text { tradição; ainda outros podem } \\
\text { optar por desenvolver } \\
\text { alternativas para sua forma de } \\
\text { gestão, inovando nas práticas } \\
\text { cotidianas. }\end{array}$ \\
\hline $\begin{array}{l}\text { Da família à empresa: } \\
\text { metodologia } \\
\text { diagnóstico e intervenção } \\
\text { sistêmico-psicodinâmica }\end{array}$ & $\begin{array}{l}\text { PEÇANHA, } \\
\text { Dóris Lieth. } \\
2013\end{array}$ & $\begin{array}{l}\text { Estudo } \\
\text { de caso }\end{array}$ & $\begin{array}{l}\text { Estudo de } \\
\text { caso } \\
\text { sistêmico- } \\
\text { psicodinâmic } \\
\text { o, } \\
\text { adaptados ao }\end{array}$ & $\begin{array}{l}\text { Os protocolos } \\
\text { anteriormente, haviam sido, } \\
\text { elaborados para a avaliação e } \\
\text { tratamento de famílias (Pérez- } \\
\text { Ramos \& Peçanha, 1999; } \\
\text { Peçanha, Pérez-Ramos } \\
\text { \& Lacharité, 2003) foram }\end{array}$ \\
\hline
\end{tabular}




\begin{tabular}{|c|c|c|c|c|}
\hline & & & $\begin{array}{l}\text { contexto } \\
\text { organizacion } \\
\text { al }\end{array}$ & $\begin{array}{l}\text { adaptados para o contexto } \\
\text { organizacional } \\
\text { minunciosamente apresentados, } \\
\text { visando favorecer sua utilização } \\
\text { em } \\
\text { empreendimentos familiares e } \\
\text { em outros estudos. Esses } \\
\text { instrumentos fornecem } \\
\text { elementos capazes de colaborar } \\
\text { com o diagnóstico, intervenções } \\
\text { eficazes e consequente } \\
\text { continuidade dos negócios, } \\
\text { particularmente em momentos } \\
\text { de crise } \\
\text { ou de sucessão familiar, que } \\
\text { exigem importante tomada de } \\
\text { decisão dos dirigentes. }\end{array}$ \\
\hline $\begin{array}{l}\text { Racionalidades em Jogo } \\
\text { em um Processo de } \\
\text { Profissionalização } \\
\text { Organizacional }\end{array}$ & $\begin{array}{l}\text { MUZZIO, } \\
\text { Henrique. } \\
2012\end{array}$ & $\begin{array}{l}\text { Estudo } \\
\text { de caso }\end{array}$ & $\begin{array}{l}\text { Entrevistas } \\
\text { em três } \\
\text { unidades } \\
\text { empresárias }\end{array}$ & $\begin{array}{l}\text { Os resultados sugerem uma } \\
\text { degradação dos ideais do } \\
\text { fundador diante do discurso } \\
\text { modernizante implantado pelos } \\
\text { gestores profissionais. Observa- } \\
\text { se uma diluição do seu legado } \\
\text { em nome de outros valores, os } \\
\text { quais foram associados a uma } \\
\text { questão de competitividade e de } \\
\text { longevidade organizacional. }\end{array}$ \\
\hline
\end{tabular}

Os autores que compõe esta categoria são Carrieri, Perdigão e Aguiar (2014), Peçanha (2013) e Muzzio (2012). Observando os traços de tradicionalidade das empresas familiares entende que a gestão seja feita pelo próprio fundador, sucessor, ou membro da família.

É afirmado a presença de traços de tradicionalidade nas práticas de gestão, uma vez que, os gestores compõe seu aprendizado organizacional pelas experiências diárias, mas essa tradicionalidade pode ser substituída por práticas inovadoras e alguns gestores optam por essas práticas (CARRIERI, PERDIGÃO E AGUIAR, 2014; MUZZIO, 2012).

Apesar dos valores organizacionais passarem por mudanças conforme as exigências do mercado a gestão das empresas familiares possui traços de tradicionalidade que atribui ao fundador a obrigação de formar e transmitir a visão do negócio, de maneira que permaneça ao passar pela sucessão (MUZZIO, 2012).

As empresas familiares preservam aspectos que permanecem por muitos anos, sendo esta uma característica peculiar que a distingue. Não devem ser desconsiderados os conhecimentos aprendidos na prática (CARRIERI, PERDIGÃO E AGUIAR, 2014; 
PEÇANHA, 2013). Nos resultados da pesquisa de Muzzio (2012), percebe-se que há uma predominância de uso do conhecimento científico, assim a gestão tradicional é cada vez mais silenciada e substituída por estes conhecimentos, enquanto a adesão aos valores modernos se dar por ser considerados mais competitivos.

Peçanha (2013), apresenta uma estratégia de gestão que colabora em diversos aspectos críticos, ajudando na tomada de decisões, intervenções eficazes, diagnóstico e manutenção do negócio. Sabemos que as empresas familiares passam por momentos de grandes dificuldades que exigem tomadas de decisões eficazes, considera-se que recorrer a instrumentos de gestão seja uma boa opção para minimizar os erros. Ainda segundo Peçanha (20013), supõe que e a tomada de decisões envolvem conflitos e são motivadas por demandas internas e externas e para que aconteça mudança é preciso um aprendizado e um desenvolvimento grupal. Muzzio (2012), fala que o comportamento do fundador influencia as gestões futuras.

\section{Categoria 3- Empresa Familiar e Sucessão}

Nesta categoria foram agrupados os artigos que discutiram sobre empresa familiar e sucessão, assim podemos ver no quadro 03, as informações correspondentes a cada trabalho desta categoria.

Quadro 03. Empresa Familiar e Sucessão

\begin{tabular}{|l|l|l|l|l|}
\hline \multicolumn{1}{|c|}{ Título } & Autor/Ano & $\begin{array}{c}\text { Tipo de } \\
\text { Estudo }\end{array}$ & \multicolumn{1}{|c|}{ Amostra } & \multicolumn{1}{c|}{ Resultados } \\
\hline $\begin{array}{l}\text { Sucessão, } \\
\text { profissionalização e } \\
\text { governança: um estudo } \\
\text { multicasos em empresas } \\
\text { familiares Mineiras }\end{array}$ & $\begin{array}{l}\text { PEREIRA, } \\
\text { Rafael } \\
\text { Diogo. } \\
2010\end{array}$ & $\begin{array}{l}\text { O estudo } \\
\text { Multicasos }\end{array}$ & $\begin{array}{l}\text { Três } \\
\text { empresas } \\
\text { familiares } \\
\text { mineiras } \\
\text { pertencentes } \\
\text { ao setor têxtil, } \\
\text { à área de } \\
\text { transportes e à } \\
\text { atividade } \\
\text { cafeeira. }\end{array}$ & $\begin{array}{l}\text { Verificou-se que a construção } \\
\text { da governança nas empresas } \\
\text { familiares deve ser entendida } \\
\text { como um processo por meio } \\
\text { do qual o consenso entre os } \\
\text { atores envolvidos pode ser } \\
\text { estabelecido, considerando os } \\
\text { valores familiares, a tradição } \\
\text { o poder historicamente } \\
\text { concentrado nos dirigentes } \\
\text { destas organizações. }\end{array}$ \\
\hline $\begin{array}{l}\text { Paradigma da empresa } \\
\text { versus paradigma da }\end{array}$ & $\begin{array}{l}\text { MALTZ, } \\
\text { Ricardo }\end{array}$ & $\begin{array}{l}\text { Bibliográfi } \\
\text { co }\end{array}$ & $\begin{array}{l}\text { livros } \\
\text { produções }\end{array}$ & $\begin{array}{l}\text { A conflitiva gerada pelo } \\
\text { choque dos paradigmas da }\end{array}$ \\
\hline
\end{tabular}




\begin{tabular}{|c|c|c|c|c|}
\hline $\begin{array}{l}\text { família e a sucessão em } \\
\text { empresas familiares: } \\
\text { fatores que obstaculizam } \\
\text { o processo sucessório e } \\
\text { colocam em risco a } \\
\text { perenização da empresa } \\
\text { familiar }\end{array}$ & $\begin{array}{l}\text { Gus. } \\
2010\end{array}$ & & $\begin{array}{l}\text { científicas } \\
\text { publicadas em } \\
\text { meio } \\
\text { específico }\end{array}$ & $\begin{array}{l}\text { empresa e da família é } \\
\text { insolúvel e medicável na } \\
\text { medida em que for regrado; a } \\
\text { transferência de poder e } \\
\text { liderança são de tamanha } \\
\text { complexidade que extrapola o } \\
\text { simples ato de transferência } \\
\text { e, a tensão e desarmonia } \\
\text { gerada no grupo que convive } \\
\text { com tal processo pode tornar- } \\
\text { se um obstáculo e em muito } \\
\text { dificultar o processo de } \\
\text { sucessão dado seu modo de } \\
\text { agir e laços que estabelece } \\
\text { com seu líder eleito. }\end{array}$ \\
\hline $\begin{array}{l}\text { A sucessão da empresa } \\
\text { familiar: } \\
\text { importância dos pactos } \\
\text { paras sociais e outros } \\
\text { instrumentos relevantes } \\
\text { para a preservação da } \\
\text { empresa e da } \\
\text { propriedade familiar }\end{array}$ & $\begin{array}{l}\text { NÓBREGA } \\
\text { ' João } \\
\text { Rafael de } \\
\text { Farias } \\
\text { Furtado. } \\
2012\end{array}$ & $\begin{array}{l}\text { Revisão de } \\
\text { literatura }\end{array}$ & $\begin{array}{l}\text { Literatura } \\
\text { especializada }\end{array}$ & \begin{tabular}{lr}
\multicolumn{2}{l}{ Como conclusão, é observado } \\
o fato de que empresas \\
familiares & longevas \\
provavelmente & sobreviveram \\
ao desafio da & sucessão, pois \\
conseguiram & estabelecer \\
nível de & comunicação, \\
interação e amadurecimento \\
que lhes & permitiram \\
implementar as mudanças \\
necessárias \\
transferência \\
comando.
\end{tabular} \\
\hline $\begin{array}{l}\text { A problemática da } \\
\text { sucessão em empresas } \\
\text { familiares } \\
\text { instrumentalização da } \\
\text { governança corporativa: } \\
\text { um estudo de caso }\end{array}$ & $\begin{array}{l}\text { MATESCO } \\
\text {,Kren. } \\
2014\end{array}$ & $\begin{array}{l}\text { Revisão de } \\
\text { literatura }\end{array}$ & $\begin{array}{l}\text { Pesquisa } \\
\text { através da livre } \\
\text { leitura sobre os } \\
\text { diversos } \\
\text { recortes que } \\
\text { tratam de } \\
\text { empresa } \\
\text { familiar }\end{array}$ & $\begin{array}{l}\text { O estudo apresenta que muito } \\
\text { embora tenham } \\
\text { experimentado uma vida } \\
\text { pregressa de } \\
\text { empresarial, quando essas } \\
\text { organizações estão diante do } \\
\text { processo sucessório, se veem } \\
\text { diante de seu momento mais } \\
\text { crítico. Isso porque o sucesso } \\
\text { desse tipo de organização é } \\
\text { normalmente atribuído à } \\
\text { existência de traços pessoais } \\
\text { do fundador. }\end{array}$ \\
\hline $\begin{array}{l}\text { Desconstrução do Mito e } \\
\text { Sucessão do Fundador } \\
\text { em Empresas Familiares }\end{array}$ & $\begin{array}{l}\text { PEREIRA, } \\
\text { Antonio } \\
\text { Carlos } \\
\text { Soares. et } \\
\text { al. } \\
2013\end{array}$ & $\begin{array}{l}\text { Estudo de } \\
\text { caso }\end{array}$ & $\begin{array}{l}\text { Um grupo } \\
\text { empresarial } \\
\text { familiar, } \\
\text { denominado de } \\
\text { O. G., formado } \\
\text { por } \\
\text { empresas } \\
\text { atividade } \\
\text { cinco } \\
\text { desativadas, } \\
\text { localizadas no } \\
\text { estado }\end{array}$ & $\begin{array}{l}\text { A análise dos dados revela } \\
\text { que os fatores } \\
\text { contribuíram mais } \\
\text { desconstrução para } \\
\text { foram: a sua recusa em } \\
\text { abordar temas relacionados a } \\
\text { conflitos familiares; o } \\
\text { comportamento } \\
\text { centralização e autoritarismo } \\
\text { do mito; e a não transmissão } \\
\text { do empreendedorismo para a } \\
\text { geração sucessora. }\end{array}$ \\
\hline
\end{tabular}




\begin{tabular}{|c|c|c|c|c|}
\hline & & & Minas Gerais & \\
\hline $\begin{array}{l}\text { Ciclo de vida, sucessão e } \\
\text { processo de governança } \\
\text { em uma empresa } \\
\text { familiar: um estudo de } \\
\text { caso no grupo seculus }\end{array}$ & $\begin{array}{l}\text { CANÇADO } \\
\text {,Vera L. et } \\
\text { al. } \\
2013\end{array}$ & $\begin{array}{l}\text { Estudo de } \\
\text { caso } \\
\text { descritivo }\end{array}$ & $\begin{array}{l}\text { Familiares não } \\
\text { acionistas } \\
\text { empregados e } \\
\text { não } \\
\text { empregados da } \\
\text { empresa e } \\
\text { gestores } \\
\text { não } \\
\text { pertencentes à } \\
\text { família. }\end{array}$ & $\begin{array}{l}\text { A condução da sucessão em } \\
\text { empresas familiares envolve } \\
\text { desafios relativos ao } \\
\text { desenvolvimento de famílias, } \\
\text { da empresa e da propriedade. } \\
\text { Tais desafios são bem } \\
\text { encaminhados quando } \\
\text { passam pela criação de } \\
\text { estruturas que permitem à } \\
\text { família proprietária } \\
\text { participar das soluções, } \\
\text { equacionadas por práticas de } \\
\text { governança. }\end{array}$ \\
\hline 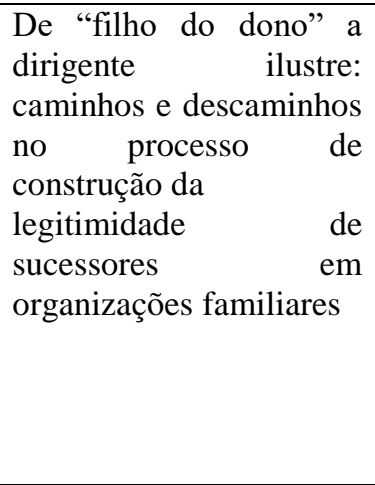 & $\begin{array}{l}\text { OLIVEIRA, } \\
\text { Janete Iara } \\
\text { de. } \\
\text { ALBUQUE } \\
\text { RQUE, Ana } \\
\text { Luiza. } \\
\text { PEREIRA, } \\
\text { Rafael } \\
\text { Diogo. } \\
2013\end{array}$ & $\begin{array}{l}\text { Estudo de } \\
\text { caso }\end{array}$ & $\begin{array}{l}\text { Constituído } \\
\text { por dirigentes } \\
\text { familiares } \\
\text { pertencentes a } \\
\text { duas empresas } \\
\text { familiares } \\
\text { mineiras de } \\
\text { grande } \\
\text { porte. }\end{array}$ & $\begin{array}{l}\text { Os resultados indicam que a } \\
\text { empresa efetivamente se } \\
\text { constitui como uma instância } \\
\text { de socialização primária, } \\
\text { pela qual perpassa a ideia de } \\
\text { comprometimento } \\
\text { com a continuidade do } \\
\text { negócio da família. }\end{array}$ \\
\hline $\begin{array}{l}\text { Processo de sucessão em } \\
\text { empresa familiar: gestão } \\
\text { do conhecimento } \\
\text { contornando resistências } \\
\text { às mudanças } \\
\text { organizacionais }\end{array}$ & $\begin{array}{l}\text { FREIRE, } \\
\text { Patricia de } \\
\text { Sá.et al } \\
2010\end{array}$ & $\begin{array}{l}\text { Estudo } \\
\text { descritivo } \\
\text { qualitativo }\end{array}$ & $\begin{array}{l}\text { Entrevistas e } \\
\text { análise } \\
\text { Documental }\end{array}$ & $\begin{array}{l}\text { O maior destaque desta } \\
\text { análise fica na identificação } \\
\text { da percepção negativa dos } \\
\text { colaboradores quanto a sua } \\
\text { não participação nas } \\
\text { tomadas de decisões que } \\
\text { afetam suas rotinas e áreas. }\end{array}$ \\
\hline
\end{tabular}

As bases de dados SCIELO e BDTD possui uma variedade de publicações que abordam o tema de sucessão em empresa familiar, os selecionados estão em maior quantidade nesta categoria, chegando a 08 trabalhos.

Os autores aqui evidenciados são Pereira (2010), Maltz (2010), Nóbrega (2012), Matesco (2014), Pereira et al. (2013), Cançado et al. (2013), Oliveira, Albuquerque, Pereira(2013), Freire. et al.,(2010).

Podemos observar nos principais achados, que a sucessão é percebida como um obstáculo para a continuidade do negócio e é gerador de conflitos e medos. Cançado.et al.,(2013), aborda a proposta de sucessão como desafiadora para a família e abre uma 
possiblidade de discursão que diz respeito ao estabelecimento de práticas de governança que estruture a sucessão.

Matesco (2014), apresenta um discurso próximo do que Cançadoet al. (2013) expõe, a sucessão como evento crítico, na qual buscam no sucessor aspectos comportamentais próximos ao apresentado pelo fundador. Nóbrega (2012) e Freire. et al.,(2010), relata que este evento requer medidas que permita a passagem do poder, assim, traz a comunicações, a interação e o amadurecimento como práticas facilitadoras neste processo.

Os artigos trazem o sentimento de continuidade do patrimônio e o contrato impessoal da herança de hereditariedade como princípios norteadores para passagem do poder e liderança, ressaltam que podem se transformar em obstáculo a este processo, a tensão e a desarmonia, bem como, a falta de transmissão da visão empreendedora, já os valores e a tradicionalidade estabelece as regras de sucessão (PEREIRA, 2010; OLIVEIRA; ALBUQUERQUE; PEREIRA, 2013; MALTZ, 2010).

A governança é uma estrutura que oferece suporte a este processo e necessita está junto com os valores e tradição e estarem em consenso com os demais colaboradores e membros da família (CANÇADO. et al., 2013; PEREIRA. et al., 2013)

Os autores como Maltz (2010), Oliveira, Albuquerque (2013) e Pereira (2010), trazem uma ideias de comprometimento com a continuidade da propriedade da família atrelado aos valores sociais que a organização adquiriu.

\section{Categoria 4- Cultura Organizacional e Empresa Familiar}

Nesta categoria foram agrupados os trabalhos que abordam conteúdos relativos à cultura organizacional e empresa familiar. As informações do artigo incluído esta contido no quadro04.

Quadro 04. Cultura Organizacional e Empresa Familiar

\begin{tabular}{|c|c|c|c|c|}
\hline Titulo & Autor/Ano & $\begin{array}{l}\text { Tipo de } \\
\text { Estudo }\end{array}$ & Amostra & Resultados \\
\hline 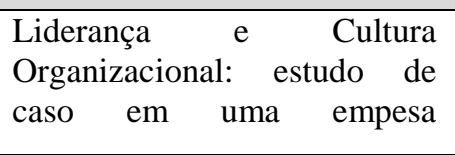 & $\begin{array}{l}\text { Coury, } \\
\text { Cibele. } \\
2014\end{array}$ & $\begin{array}{l}\text { Estudo } \\
\text { de Caso }\end{array}$ & $\begin{array}{l}\text { Empresa } \\
\text { familiar } \\
\text { fundada }\end{array}$ & $\begin{array}{l}\text { A cultura, criada e consolidada por } \\
\text { meio da relação de troca mútua } \\
\text { entre líder e liderado, foi }\end{array}$ \\
\hline
\end{tabular}


Id on Line Revista Multidisciplinar e de Psicoloqia

Id on Line Multidisciplinary and Psycology Journal

\begin{tabular}{|c|c|c|}
\hline $\begin{array}{l}\text { manufatureira de origem } \\
\text { familiar }\end{array}$ & $\begin{array}{l}\text { na década } \\
\text { de } 1960\end{array}$ & $\begin{array}{l}\text { observada e os fatores emocionais } \\
\text { relacionados á personalidade do } \\
\text { líder, seu comportamento, suas } \\
\text { crenças e pressupostos, } \\
\text { identificados. Sob a prerrogativa } \\
\text { de Schein (2009), que versa sobre } \\
\text { a forma como os subordinados } \\
\text { absorvem a cultura dos dirigentes, } \\
\text { pode-se observar um paralelo entre } \\
\text { a dinâmica da família dirigente e a } \\
\text { cultura da organizacão. }\end{array}$ \\
\hline
\end{tabular}

O quadro 4 apresenta o único estudo selecionado que aborda os dois temas conjuntamente: cultura organizacional e empresa familiar. Fica evidente a necessidade de futuras pesquisas nesta área, pois considera pouco representativo a amostra de um artigo, em relação aos 6 anos de intervalo a qual coletou-se os trabalho.

O trabalho de Coury (2014), consiste em um estudo de caso. Com o intuito de abordar a dinâmica de liderança da família, foi analisada uma Empresa familiar fundada na década de 1960.

Faz referência ao autor Edgar Schein, por ser um pesquisador da cultura organizacional e apresentá-la de forma ampla e profunda, o referencial bibliográfico da autora que aborda este tema tem em grande parte a contribuição deste autor.

Coury (2014), apresenta conceitos da cultura organizacional sob a visão de diversos autores, fala que a cultura organizacional está relacionada com a tradição e a história da organização, esta cultura é aceita coletivamente por um dado período de tempo e exerce uma influência nas decisões e visões do negócio. Os pesquisadores da área, citados na dissertação da autora, apresentam conceitos distintos de cultura organizacional.

Evidencia que os valores do fundador só serão confirmados e mantidos na organização se levá-la ao sucesso, promovendo satisfação e ajudando no cumprimento dos objetivos, só então serão adotados e compartilhados.

Para a autora, a cultura organizacional não é herdada, mas construída. Distingue-se da cultura social e da personalidade de cada um. Os membros da família proprietária e colaboradores são os principais atuantes na cultura e na construção e manutenção desta. Assim considera-se que a construção desta é permeada pelas práticas organizacionais. 


\section{Considerações Finais}

O presente trabalho foi norteado pela pergunta: quais são os aspectos peculiares das empresas familiares?Os aspectos identificados foram: influência da família na tomada de decisões; transmissão de valores pessoais do fundador; relações tradicionais; sucessão familiar; gestão familiar. Sendo percebido e identificado na produção científica que a cultura organizacional está relacionada com a tradição e a história da organização.

Este artigo foi construído através da perspectiva da revisão bibliográfica sistemática e os resultados analisados sobre a metodologia da metassíntese qualitativa. Considera-se que com esses instrumentos de coleta e análise de dados conseguiu reunir evidencias necessárias, apresentadas por diferentes autores que contribuíram para o alcance dos objetivos.

O artigo reuniu conteúdos que falam sobre a empresa familiar, mas é preciso esclarecer que esta é singular em sua maneira de operar e as características aqui apresentadas podem não condizerem em total concordância com a prática vivenciada por estas organizações, considerando as limitações deste trabalho.

As empresas familiares também apresentam aspectos comuns a outras empresas, no entanto a interação família-empresa criam características singulares. O estudo da família é importante, pois a família causa impacto no negócio e traz uma história atrelada a organização. Portanto, propõe pesquisas nesta área, bem como, pesquisas que mostre as dificuldades que o primogênito enfrenta ao assumir a sucessão.

O trabalho exibe uma breve revisão de literatura acerca do tema cultura organizacional e empresa familiar, com o intuito de informar aos leitores a amplitude do tema abordado. Conclui-se que, empresas familiares são dinâmicas e necessitam ser pesquisadas em abrangência, pois contribuem com grande parte da economia do país, desta maneira apresentar conteúdos que ajudem a essas organizações se manterem ativa, principalmente nesta época de crise econômica nacional, considera-se uma prática de grande contribuição social.

\section{Referências}


BOTTOLI, Cristiane, et al.;Transformações da Família Nuclear para a Família Contemporânea: Novas Configurações (2012). $5^{\circ}$ interfaces no fazer psicológico, direitos humanos, diversidades e diferenças. Santa Maria/UNIFRA, 2012. Disponível em $\langle$ http://www.unifra.br/eventos/interfacespsicologia/Trabalhos/3081.pdf $>$. Acesso em: 15 de março de 2016.

CARNEIRO, Ângela Patrícia Linard. Diagnóstico da Gestão do Conhecimento em uma Empresa Familiar a Partir de Práticas de Gestão Administrativa. João Pessoa, 2008. Disponível em<http://livros01.livrosgratis.com.br/cp079517.pdf> acesso em: 19 marços 2016.

CASTRO, A. A. Revisão Sistemática e Meta-análise. In: GOLDENBERG, S.; GUIMARÃES, C. ALBERTO; CASTRO, A. A (Ed.) Elaboração e Apresentação de Comunicação Científica.São Paulo, 2009. p. 1-11. Disponível em:<http://metodologia.org/wpcontent/uploads/2010/08/meta1.PDF>. Acesso em: 30 abril 2016.

CHIAVEnAto, Idalberto. Gestão de Pessoas: O Novo Papel dos Recursos Humanos nas Organizações. 3. ed. Rio de janeiro: Elsevier, 2008

DAVIDOFF, Linda L. Introdução á Psicologia. 3. Ed. Tradução Lenke Peres; revisão técnica José Fernando Bittencourt Lômaco. São Paulo: Person Makron Books, 2001

DRUCKER. Peter Ferdinand. Inovação e Espirito Empreendedor: Prática e Princípios. São Paulo: Cengage Learning, 2014.

FERREIRA, Patricia Itala Clima organizacional e qualidade de vida no trabalho / Patricia Itala Ferreira ; organização Andrea Ramal. - Rio de Janeiro : LTC, 2013. il. ; 23 cm(MBA Gestão de Pessoas)

FREITAS, João Paulo. Passagem do Bastão, o Grande Impasse na Empresa Familiar. Gazeta mercantil. São Paulo; 03/10/2008. Disponivel em: <http://www.comunicare2.com.br/cartarh/properties.asp?txtCode=34997> Acesso em: 18 de abril 2016.

GIL, Antonio Carlos. Como Elaborar Projetos de Pesquisa. 5 ed. SãoPaulo: Atlas, 2010.

GOMES, Isabelle Sena; CAMINHA,Iraquitan de Oliveira.Guia para estudos de revisão sistemática: uma opção metodológica para as Ciências do Movimento Humano.Movimento, Porto Alegre, v. 20, n. 01, p. 395-411, jan/mar de 2014. Disponível em<http://www.seer.ufrgs.br/Movimento/article/viewFile/41542/28358> acesso em: 29 abril 2016.

HORST. Ana Carolina; SOBOLL, Lis Andréa Pereira; CICMANEC, Édna. Prática de gestão e controle da subjetividade dos trabalhadores: a ideologia de encantamento em uma empresa de varejo. Cad. psicol. soc. trab., Jun 2013, vol.16, no.1, p.9-23. ISSN 1516-3717. Disponível em<http://www.revistas.usp.br/cpst/article/view/77736/81727> Acesso em: 20 março 2016.

LEONE, Nilda Maria de Clodoaldo Pinto et al. Empresa familiar: identificação das repercussões econômicas, tecnológicas e organizacionais por meio da trajetória dos sucessores. Revista de Administração Mackenzie, v. 7, n. 3, 2006. 
MALANCHEN, Julia. O Conceito de Cultura: Definição e Compreensão a Partir da Teoria Marxista. Cascavel, 2013. $\quad$ Disponível em <http://www.histedbr.fe.unicamp.br/acer_histedbr/jornada/jornada11/artigos/3/artigo_simposio_3_945 _julia_malanchen@hotmail.com.pdf> Acesso em: 12 de março de 2016.

MEDINA, E. U.; PAILAQUILÉN, R. M. B. A revisão sistemática e a sua relação com aprática baseada na evidência em saúde. Revista Latino-Americana de Enfermagem, Ribeirão Preto, v. 18, n. 4, p. 1- 8, jul./ago. 2010. Disponível em: 〈http://www.scielo.br/pdf/rlae/v18n4/pt_23.pdf>. Acesso em: 10 nov. 2013.

MORAES, Marcelo B. Estilo de Liderança como um Diferencial Competitivo em uma Organização Familiar: O Caso Magazine Luiza. 2006. 112 f. Dissertação (mestrado em administração)-Escola de Administração da Universidade Federal da Bahia, Bahia. 2006.

NISHITSUJI, Denny Amari. O Processo de Sucessão em Organizações Familiares na Microrregião de Cornélio Procópio. Curitiba, 2009. Disponível em <http://dspace.c3sl.ufpr.br/dspace/bitstream/handle/1884/18546/Dissertacao\%20Denny.pdf?sequence= 1> Acesso em: 04 de abril de 2016.

OLIVEIRA, Adélia, et al. Metassíntese: Apontamentos para sistematização de revisões amplas e crítica interna à produção científica. CIAIQ2015, v. 1, 2015. Disponível em https://scholar.google.com.br . Acesso em 04 de abril de 2016.

OLIVEIRA, Áurea de Fátima; and SOUZA, Marcos Aguiar de. Confiança do Empregado na Organização: O Impacto dos Valores Pessoais e Organizacionais. Rev. Psicol., Organ. Trab., Jun 2014, vol.14, no.2, p.204-217. ISSN 1984-6657. Disponível em http://pepsic.bvsalud.org/pdf/rpot/v14n2/v14n2a07.pdf. Acesso em 30 março 2016.

REINHARD, Nicolau. Editorial Revista de Administração - RAUSP [en linea] 2015, 50 (EneroMarzo) : [Fecha de consulta: 11 de agosto de 2016] Disponible en:<http://www.redalyc.org/articulo.oa?id=223438298001> ISSN 0080-2107

ROTHMANN, Ian; COOPER, Cary. Fundamentos de Psicologia Organizacional e do Trabalho. Tradução de Luiz Claudio de Queiros. Rio de Janeiro: Elsevier, 2009.

RUSSO, Giuseppe. Diagnóstico da Cultura Organizacional: O Impacto dos Valores Organizacionais no Desempenho das Terceirizações. Rio de Janeiro: elsevier, 2010.

SCHEIN, Edgar H. Cultura Organizacional e Liderança. Tradução Ailton Bomfim Brandão; Revisão técnica Humberto Mariotti. São Paulo: Atlas, 2009.

SEBRAE. No Brasil, 90\% das Empresas são Familiares. Artigo publicado em 03/10/2005. Disponível em: $<$ http://www.sebrae-sc.com.br/newart/default.asp?materia=10410>Acesso em: 08 de Abril de 2016.

SILVA, Jader Cristiano de Souza. Gestão Empresarial: Administrando Empresas Vencedoras. São Paulo: Saraiva, 2006.

ZANELLI, José Carlos; ANDRADE, Jairo Eduardo B. BASTOS; BASTO, Antonio Virgilio Bittencourt. Psicologia, Organizações e Trabalho no Brasil. Porto alegre: Artmed, 2004. 
Id on Line Revista Multidisciplinar e de Psicoloqia

Id on Line Multidisciplinary and Psycology Journal

\section{Como citar este artigo (Formato ABNT):}

SOUZA, Esraelyne O.; MARANHÃO, Thércia L.G.; LEONE, Nilda Maria C.P.G.; OLIVEIRA, Gislene F. Cultura Organizacional em Empresa Familiar: Uma Revisão Sistemática. Id on Line Revista Multidisciplinar e de Psicologia, Maio de 2017, vol.11, n.36, p.13-36. ISSN: 1981-1179.

Recebido: 04.06.2017

Aceito: 09.06. 2017 